\title{
Effects of Color Appeal, Perceived Risk and Culture on User's Decision in Presence of Warning Banner Message
}

\author{
Mario Silic \\ University of St Gallen \\ mario.silic@unisg.ch
}

\author{
Dianne Cyr \\ Simon Fraser \\ University \\ cyr@sfu.ca
}

\author{
Andrea Back \\ University of St Gallen \\ andrea.back@unisg.ch
}

\author{
Adrian Holzer \\ EPFL \\ adrian.holzer@gmail.c \\ om
}

\begin{abstract}
Color is present in every aspect of human life, and color is driving our decisions. In the digital computer warning realm, in which a warning message is a communication mechanism, color represents an important design element, which aims at preventing the hazard and reducing negative outcomes from the user's action. Interestingly, we are lacking the understanding of how color appeal influences behavioral intentions in culturally distinct countries when it comes to paying more attention to warning messages. We conducted a cross-cultural investigation by running an online experiment, followed by a survey of 258 participants from the United States and India. Supported by the color-in-context theory, we found that culture is an important dimension in the specific warning message context in which color appeal is a salient antecedent to behavioral intentions in culturally distinct countries. We derive several theoretical contributions and practitioners' insights.
\end{abstract}

\section{Introduction}

Color is present in every aspect of human life, be it chromatic (e.g. red) or achromatic (e.g. white). As such, color is driving our decisions as we choose what clothes to wear or which car color to pick - or even our communication processes as we comment on someone's hair or skin color. An important amount of research has addressed the complex color dimension in the following areas: color physics (color definition and modelling), color physiology and neuroscience (how the eye and brain process color stimuli), color linguistics and categorization (color representation in language), and many other color-related topics such as color reproduction and deficiency. However, "what is surprising about the color literature is the relative paucity of scientifically based research that has been conducted on color psychology in humans (i.e., the relation between color and affect, cognition, and behavior" [1]. Interestingly, not only are we lacking empirical and theoretical work on color-psychological relationship [2], but we are also seeing different statements about this relationship as a product of intuition, wrong information or scant empirical work of questionable quality [1-3].

In the digital computer warning realm, in which a warning message represents communication designed to prevent users from hurting themselves or others [4], color represents an important design element that aims at preventing the hazard and reducing negative outcomes [5-7].

This is partly explained by the fact that many warning messages are based on a "trial and error" approach rather than on persuasion or communication theories [8].

Another explanation stems from the color's contextual surround. In particular, in a cultural context, some colors (e.g. white, black and red) have default meanings which differ (e.g., in India, purity for white; or in the U.S., danger for red). This default meaning of red was also adopted in the warning message context in which a red color of warning signals danger and calls for the user's attention [9]. Although red is commonly associated with the danger of failure, the literature on red's psychological effects has ignored the issue of cultural generality or specificity [10].

According to color-in-context theory [1], the influence of color on affect, cognition and behavior is a function of the psychological context in which the color is perceived. According to Noiwan and Norcio [11]: "empirical investigations on the impacts of cultural factors on interface design are absolutely vital... Interface designers need to understand color appreciation and color responses of people in different cultures and regions." Supported by the color-incontext theory, we argue that culture is an important dimension that has not been adequately addressed in the specific warning message context (cultural dimension). Hence, we aim to answer the following research questions: 1) How does a color application (red, yellow and green) in diverse cultural groups impact color appeal? and 2) Does increased color 
appeal impact behavioral antecedents such as perceived risk and self-efficacy?

\section{Theoretical framework}

\subsection{Color-in-context theory}

The color-in-context theory suggests that there is a strong link between color and psychological reasoning [1]. The central premise of the color-in-context theory is that the influence of color on affect, cognition and behavior will depend on the psychological context in which the color is perceived. The theory suggests that context has been largely ignored in empirical and theoretical studies. According to the Color-Culture Chart devised by Russo [12], different colors will be perceived differently in another cultural environment. For instance, red in China means happiness, while red signals danger in American culture.

Another important premise of color-in-context theory is that viewing color influences psychological functioning in such a way that it is consistent with the color's meaning. In other words, when users are experiencing the color, their evaluative process will appraise stimuli as being hospitable or hostile [13-15]. The hospitable dimension increases appetitive affect (e.g. hope), cognition (e.g. being more flexible), or behavior (e.g. overt approach). On the other side, the hostile view means aversive affect (e.g. fear), cognition (e.g. narrow processing) and behavior (e.g. overt avoidance) [16-18].

Further, the meanings and effects of color are strongly linked to both biologically based and learned sources [2]. According to Elliot [2] "some colormeaning links, especially those that are observed across time and culture, are a product of the cognitive reinforcement and shaping (via social learning) of an initial biologically engrained predisposition." For example, a red dress can carry sexual meaning. Overall, this suggests that color meanings and effects are context specific in which the same color can have different meanings and, consequently, different effects on the perceiver.

\subsection{Color and decision-making}

Digital warning messages are proposed to the user as the last line of defense against potentially dangerous outcomes, and meaning is conveyed through their content and design elements (e.g., warning logo).
Although recent research has introduced "opinionated design" (use of visual design cues to promote a recommended course of action) [19], usually the decision the user must take is a binary outcome (Continue or Exit). Furthermore, the warning message as an element of visual design is mostly adapted from other disciplines. Overall, in the computer realm context, it is assumed that the red color in the decisionmaking process is associated with a negative connotation and should lead to aversive implications. Consequently, the majority of recent warning implementations (e.g. Chrome, Internet Explorer, Firefox), have implemented red as the standard and dominant color. However, red color's impact on risktaking behavior has not yet been explicitly investigated [20]. Although a number of studies demonstrated that red triggers avoidance motivation [e.g. 21, 22-24], several studies found a contradictory effect in which red causes risk-averse situations [e.g. 25, 26, 27] leading to positive effects (e.g. men attracted by women's red lipstick). Interestingly, in the digital warning context, studies that tried to better understand the color and risk-taking relationship are rare. This is especially true in different cultural setups in which color can have different meanings and interpretations. According to Wogalter, Conzola and Smith-Jackson [28], "warning components that are effective in one culture may not be effective in others, it is important to do cross-cultural testing of warnings whenever appropriate and possible."

\section{Hypothesis development}

Relationships between Color Appeal (CA) and Perceived Risk (PR) and Behavior Intention (BI)

Studies on color implications and effects on human preferences have been widely studied by psychologists [29]. This is because "Colors are known to possess emotional and psychological properties" [30]. We follow the definition of color appeal proposed by $\mathrm{Cyr}$ [31] that is defined as the degree to which colors in the warning message are perceived by the user as pleasing, appealing and appropriate. Hence, color appeal suggests positive emotion. Clearly, if, for example, in U.S. culture, red means "mistake" (e.g., teachers use red to correct mistakes), stop (e.g., red traffic lights) or danger (e.g., warning message), then we can expect to see a positive effect on the color appeal. In other words, if red suggests danger, then users (e.g., in U.S. culture) will more likely tend to be compliant which should lead to behavioral intenations. Overall, if the color appeal increases, meaning that the perceiver finds it pleasing, appealing and appropriate to transmit the risk message, then we can expect the user to be more 
cautious and pay attention to the warning message. Consequently, the user's behavioral intention toward being more compliant will be positively impacted across all cultures. Hence, we hypothesize:

H1: Increased level of color appeal will be positively associated with BI in all cultures

For Cunningham [32], perceived risk refers to the situation of uncertainty regarding the possible negative consequences and is viewed as expectation of losses. In the warning context, if users continue with their actions and ignore the warning message, the risk that they incur is, for example, to be infected by the malicious software that could damage their data. Hence, it is expected that if a red warning message succeeds to persuade them to be compliant, through an increased level of color appeal (e.g., red color is appropriate for their culture and their attention is increased), then we can expect to see the positive impact of CA on PR. Also, as color is one integral part of the entire warning message design, different preferences may be observed depending on the users' cultural backgrounds [33-35]. Clearly, if users find the red color to be appealing, eyecatching and appropriate in his/her culture, then we argue that the level of the perceived risk will be positively influenced by the color appeal of the warning message. Hence, we hypothesize:

H2: Increased level of color appeal will be positively associated with PR in all cultures

\section{Relationships between Perceived Risk (PR) and Behavior Intention (BI)}

In the warning message content, PR refers to the risk of clicking on continued action in which data, information and overall information integrity of users' computers would be jeopardized. The deliberate user action to continue with their browsing task indicates that users acknowledge the risk, accept it and continue with their action. Clearly, PR will influence their decisions [36] and, as such, is an important driver of the behavioral intentions. In this research, the PR construct relates to security/privacy risk in which the security or privacy dimension is vital in the decisionmaking process, as the entire process is surrounded by uncertainty, anxiety and conflict that affects the decision-maker [37]. Past research has shown that perceived risk strongly impacts the decision-maker's adoption process [e.g. 38], and its relationships with behavioral intentions [e.g. 39]. In this context, we argue that an increase of PR will be positively linked with the behavioral intentions to comply with the warning message. Hence, we hypothesize:

H3: Increased level of PR will be positively associated with BI in all cultures
Relationships between Cues to Action (CTA), Perceived Self-Efficacy (PSE) and Perceived Risk (PR)

Cues to action represent events that call for some recommended action. These could be media reports, internal organizational newsletters, social influence, or recommendations from experts. Cues to action should trigger "readiness to act" and stimulate behavior in which perception of risk should be lower. Perceived self-efficacy is one's confidence in the ability to successfully perform an action [40]. We argue that, in the presence of CTA, users will be more aware of the potential hazards and will, consequently, be more cautious, which should decrease their level of perceived risk. Similarly, if users have enough skills, knowledge and competency to recognize, understand and apprehend the warning message, then the level of the perceived risk should be lower. Hence, we hypothesize:

H4: Increased level of PSE will be positively associated with PR in all cultures

H5: Increased level of CTA will be positively associated with PR in all cultures

Relationship between Behavior Intention (BI) and Actual Behavior (ACT)

The relationship between BI and ACT is theorized in several theories such as the Theory of Reasoned Action [41], and many studies have empirically tested these theories. For instance, in Information Systems studies, BI is found to predict actual IT usage [e.g. 42, 43]. However, BI may not always lead to actual behaviors [44]. Indeed, several studies suggest that, in an information security context, it is better and more realistic to measure actual behaviors rather than intentions [44-46]. Hence, in this study, we use actual behavior (binary decision where user clicks on continue or exit in the warning message) arguing that BI will lead to actual behavior. Hence, we hypothesize:

H6: BI will be positively associated with ACT across all cultures

Relationship between Culture, Color Appeal, Perceived Risk and Behavioral Intention

Cultural Relativism suggests that color perception is defined by culturally specific associations and perceptual learning $[47,48]$. In the Internet realm, the user expects to have the website content localized [49, 50], in which content would be adapted to their own cultural specifics (e.g. color of the warning message). Past research suggests that website interface adoption and preferences for design features are different from one culture to another [51]. Moreover, color seems to be an important element that designers should take into 
account when considering visual aesthetics [33]. This is where the color appeal dimension comes into play as more appealing, interesting and eye-catching design elements are more likely to grab the user's attention. Parallel to this, if, in a certain culture, the color meaning has a different connotation (e.g., red has a negative association in U.S. culture and is positive in the Chinese culture), then we can expect to see different moderating effects on the perceived risk. Therefore, we expect to see different levels of color appeal across different cultures. That is, color appeal as related to perceived risk and behavioral intentions will be moderated by culture. We base this hypothesis on the color-in-context theory that suggests that color perception is based on context specific and, as such, should produce different effects on the user's behavior. This means that a specific culture will have expectations when it comes to the color application [49]. In other words, the same culture would expect to see the warning message adapted to its culture such that it represents the danger that users may expect in case they continue with their action. Hence, we hypothesize:

H7a: The influence of color appeal on perceived risk will be moderated by culture

H7b: The influence of color appeal on behavioral intentions will be moderated by culture

In the same vein, and supported by the color-incontext theory, we argue that color application will have different arousal effects across different cultures. That is, we expect that different colors (red, yellow and green) will be perceived differently in U.S. and Indian cultures. More precisely, as red is usually associated with fear and danger in western cultures, we expect red to transmit risky behavior in U.S. culture. In parallel, as yellow suggests sacred and auspicious dimension in Indian culture [12], we expect yellow to be the most appealing color. Hence, we hypothesize:

H8a: The most appealing color in U.S. culture will be red

H8b: The most appealing color in Indian culture will be yellow

\section{$4 \quad$ Research design}

\subsection{Participants}

In order to capture actual user behaviors, we conducted a non-controlled online experiment followed by an online survey. After receiving the Institutional Review Board (IRB) approval, we used the deception method to increase the realism of our results. Our sample consisted of two different cultures: U.S. and India. The choice was supported by their cultural diversity related to [52] country cultural dimensions: Power distance (U.S. 40, India 77); Uncertainty avoidance (U.S. 46, India 40); Masculinity (U.S. 62, India 56) and Individualism (U.S. 91, India 48). All participants were general Internet users (e.g., students, employees). Another reason for choosing the U.S. and India is based on different color perceptions of these two cultures [12]. Finally, we opted for red, green and yellow color applications as these three colors seem to be the most salient ones (red is the default warning color, yellow is frequently used in warning messages, and green represents the safety dimension). Finally, we limit our study to the U.S. and India, but, as highlighted in the limitations section, future studies could incorporate other cultures.

\subsection{Measures and procedures}

All contacted users were provided a web link, which led them to a website in which they were asked to complete a task. The task consisted of selecting the product image users liked the most. After clicking on the task "start" button, users were presented the warning banner message in which color was randomly assigned by a random function within the web application. The warning message is based on the latest Google Chrome web browser malware warning that we slightly modified (instead of using the word "malware," we used the word "safe" for simplicity and comprehension reasons).

When users clicked on "Continue" or "EXIT," their binary decision was registered on a remote database (1 for continue and 0 for Exit). Finally, users were taken to an online survey. All measures where possible were adapted from the past literature (Color appeal [31], Cues to Action [53], Perceived risk [54], Perceived self-efficacy [55], Behavior Intention [53]; [56]), and measured on an 11-point Likert scale from 0 to 10.

\subsection{Method for analysis}

Our research was built on the survey data and employs variance-based structural equation modelling (SEM). 

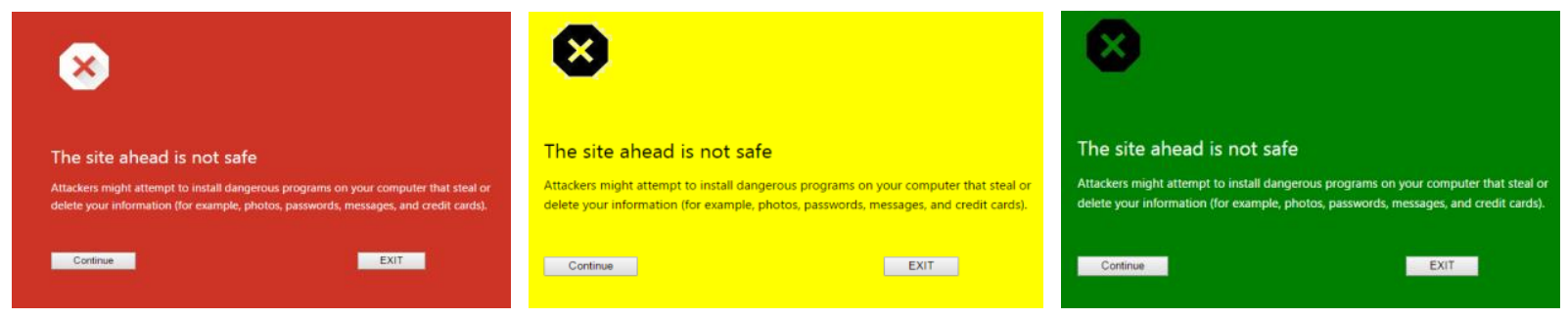

Figure 1. Warning message displayed (adapted from Google Chrome version 46)

The research model was tested using the partial least squares (PLS) approach. We opted for WarpPLS 3.0 [57], a powerful PLS-based structural equation modeling software that has the capability to test both linear and non-linear relationships (e.g., U-shaped and S-shaped functions).

\section{Results}

In this section, we present our detailed findings.

\subsection{Demographics}

Our final sample (we eliminated 38 responses for different reasons: e.g., implausible response times < 1 min) accounted for 258 participants (male 149/female 109) from two different countries (U.S. 133, India 125). Out of 258 participants, 148 were students, 82 were employed, and 28 were in other category (e.g., unemployed).

\section{$5.2 \quad$ Measurement model}

To assess the research model fit with the data, it is recommended that the $\mathrm{p}$-values for both the average path coefficient (APC) and the average r-squared (ARS) be both lower than 0.05 . Additionally, it is recommended that the average variance inflation factor (AVIF) be lower than 5 [57]. In reference to the results $(\mathrm{APC}=0.248$ and $\mathrm{ARS}=0.190$ with $\mathrm{p}<0.001, \mathrm{AVIF}=$ 1.141), all of three criteria are met in both models, and we have reason to believe that the models have acceptable predictive and explanatory quality.

Further, the composite reliabilities of the different measures range from 0.837 to 0.972 , which exceeds the recommended threshold value of 0.70 . Also, following the recommendation of Fornell and Larcker [58], the average variance extracted (AVE) for each variable construct exceeds 0.50. According to the FornellLarcker criterion [58], the AVE of each latent construct should be higher than the construct's highest squared correlation with regard to any other latent construct. Also, to conduct the discriminant validity test, we calculated the square root of the reflective construct's
AVE, which is on the diagonal, and the correlations between the constructs are in the lower left triangle. We conclude that the discriminant validity test has been established.

Next, we checked the cross loadings in which discriminant validity is established when an indicator's loading on a construct is higher than all of its cross loadings with other constructs. The results indicated that all the items are more highly loaded on their respective construct than on any other as all of the items' loadings were greater than 0.70 (all significant, $\mathrm{p}<0.001)$.

We have now reviewed the initial information by conducting a full collinearity check and checking factor loadings and cross loadings. We conclude that the initial results indicate that the model findings are meaningful.

\subsection{Common method bias}

As we collected responses from single respondents via the online survey, there is a possibility for common method bias. In an effort to minimize the susceptibility of the study to common methods bias, we provided detailed explanations and examples to all constructs and terms within the survey, which ensured higher realism leading to more responses that are valid. Also, we followed two recommendations as suggested by Podsakoff [59] to address some specific threats to common method bias: 1) before participants started the survey they read a statement that explained that there is no good or bad answer and that their honest answers are expected; and 2) we assured participants that their responses are fully anonymous. We used two procedures to check for common method variance (CMV): Harman's single factor [59] and the technique recommended by [60]. Based on both tests, we concluded that common method bias is not a concern for this research.

\section{$5.4 \quad$ Hypothesis results}

We used a structural equation modelling approach to test our hypotheses. Following the recommendation from Chin [61], we performed bootstrapping (500 sub- 
samples) to test the statistical significance of each path by examining the t-statistics. Full model results are depicted in Figure 2.

All paths from $\mathrm{H} 1-\mathrm{H} 6$ are positive and statistically significant. Thus, we can confirm that hypotheses $\mathrm{H} 1$ to $\mathrm{H} 6$ are all supported. Also, 22\% and $31 \%$ of variance for perceived risk and behavioral intention, respectively, are explained by the model that exceeds the recommended $10 \%$ benchmark as suggested by [62].

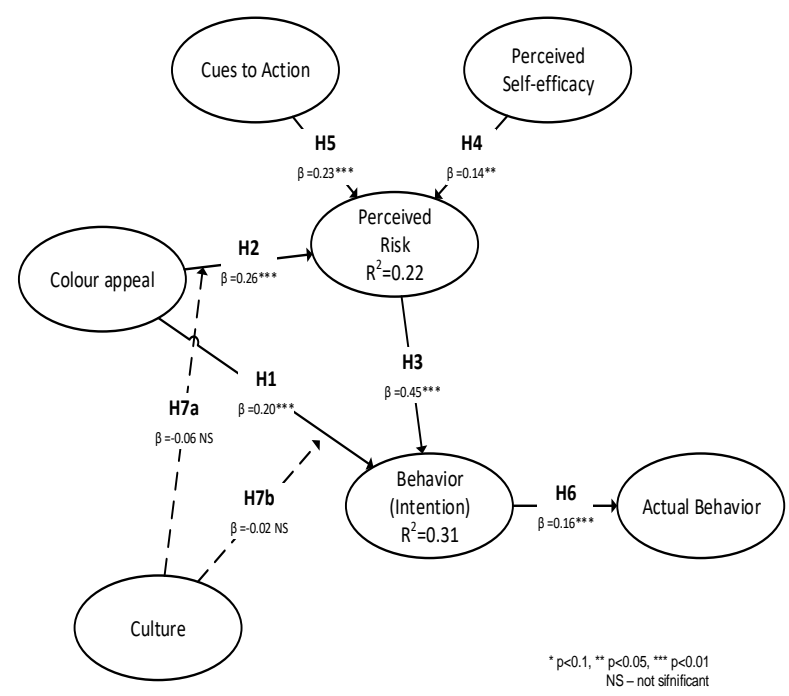

Figure 2. Full model results

Further, to test mediating effects of culture on $\mathrm{CA} \rightarrow \mathrm{PR}$ and on $\mathrm{CA} \rightarrow \mathrm{BI}$, we used WarpPLS by inspecting coefficients generated for indirect and total effects, which include $\mathrm{p}$ values. Results showed that interactions fall short of significance: $C A \rightarrow P R(\beta=$ $0.06, p=0.18)$ and $\mathrm{CA} \rightarrow \mathrm{BI}(\beta=-0.02, \mathrm{p}=0.41)$. Hence, we conclude that culture is not moderating the relationships between color appeal and perceived risk and between color appeal and behavioral intention. Thus, hypotheses $\mathrm{H} 7 \mathrm{a}$ and $\mathrm{H} 7 \mathrm{~b}$ are not supported.

\subsection{Hypothesis results for each color application}

Next, we wanted to examine the relationship between different constructs for each of the color applications. We ran SEM analysis for each country and each color application (red, yellow and green). Results are presented in Table 1. Results indicate that $\mathrm{CA}$ to $\mathrm{BEH}$ and PR is significant across all colors for the U.S. and is significant for red and green in Indian culture. Path PR $\rightarrow$ BEH is significant for both cultures and all colors. Similarly, CSE $\rightarrow$ PR is significant for all colors and both cultures, except for the green color. Finally, the BEH $\rightarrow$ ACT path is significant only in $\mathrm{red} / \mathrm{U} . \mathrm{S}$. and India, yellow/U.S. and green/India.

Next, in order to understand how color appeal differs from one culture to another and if its effects are stronger or weaker depending on the color, we run multiple comparisons tests.

More precisely, to compare relationships between colors and country and between different colors for the same country, we ran pairwise comparisons (the Tukey test).

From the results we can see that the red color is more appealing than yellow $(0.032, \mathrm{p}<0.01)$ and green $(0.023, \mathrm{p}<0.01)$ in the U.S. culture. This suggests that, in U.S. culture, red is a preferred color over yellow and green for the warning banner message. We conclude that hypothesis H8a is supported. However, we did not find any evidence to support $\mathrm{H} 8 \mathrm{~b}$, in which yellow would be the most appealing in Indian culture. Hence, $\mathrm{H} 8 \mathrm{~b}$ is not supported.

\begin{tabular}{|c|c|c|c|c|c|c|c|}
\hline \multirow[b]{2}{*}{$\begin{array}{l}\text { Colors / } \\
\text { Relationship }\end{array}$} & \multirow[b]{2}{*}{$\begin{array}{c}\text { Full model } \\
(\mathrm{N}=258)\end{array}$} & \multicolumn{2}{|c|}{ Red } & \multicolumn{2}{|c|}{ Yellow } & \multicolumn{2}{|c|}{ Green } \\
\hline & & $\begin{array}{c}\mathrm{US} \\
(\mathrm{N}=48)\end{array}$ & $\begin{array}{c}\text { India } \\
(\mathrm{N}=39) \\
\end{array}$ & $\begin{array}{c}\text { US } \\
(\mathrm{N}=44)\end{array}$ & $\begin{array}{c}\text { India } \\
(\mathrm{N}=42)\end{array}$ & $\begin{array}{c}\text { US } \\
(\mathrm{N}=41)\end{array}$ & $\begin{array}{c}\text { India } \\
(\mathrm{N}=44)\end{array}$ \\
\hline CA--> BEH & $0.20 * * *$ & $0.30 * *$ & $0.24 *$ & $0.43 * * *$ & $0.12 \mathrm{NS}$ & $0.43 * * *$ & $0.43 * * *$ \\
\hline CA--> PR & $0.26 * * *$ & $0.28 * *$ & $0.36 * * *$ & $0.33 *$ & $0.13 \mathrm{NS}$ & $0.54 * * *$ & $0.33 * * *$ \\
\hline PR-->BEH & $0.45 * * *$ & $0.49 * * *$ & $0.37 * * *$ & $0.31 *$ & $0.96 * * *$ & $0.31 * *$ & $0.25 *$ \\
\hline CSE-->PR & $0.14 * *$ & $0.21 *$ & $0.22 *$ & $0.29 *$ & $0.55 * * *$ & $-0.21 \mathrm{NS}$ & $-0.16 \mathrm{NS}$ \\
\hline CUE-->PR & $0.23 * * *$ & $0.31 * * *$ & $0.31 * * *$ & $0.16 \mathrm{NS}$ & $-0.30 \mathrm{NS}$ & $-0.10 \mathrm{NS}$ & $0.22 *$ \\
\hline BEH-->ACT & $0.16 * * *$ & $0.54 * * *$ & $0.22 * * *$ & $0.42 * * *$ & $0.06 \mathrm{NS}$ & $0.11 *$ & $0.24 *$ \\
\hline
\end{tabular}

Table 1: Results for each color application 


\section{Discussion}

In this research, we sought to answer two research questions: 1) How does a color application (red, yellow and green) in diverse cultural groups impact color appeal? and 2) Does increased color appeal impact behavioral antecedents such as perceived risk and selfefficacy? More precisely, we hypothesized positive relationships between color appeal, perceived risk and behavioral intention and between cues to action, perceived self-efficacy and perceived risk. We found support for most of our hypotheses. Although, we did not find culture to moderate color appeal/perceive risk and color-appeal/behavioral intention relationships in the full model, we found strong support for color application (red, yellow and green) having different effects on color appeal in US culture.

\subsection{Theoretical contribution}

Our research offers several new contributions to the Information Systems security literature and in particular, to the human-computer interaction field. Firstly, we uniquely applied the color appeal construct [31] in the warning message context demonstrating that color appeal is a significant predictor of perceived risk and behavioral intentions to comply with the warning message content. This finding extends past research which mostly dealt with cognitive processing [63], or trying to understand why people ignore warnings [6468]. Second, we extend the color-in-context theory to the warning context, highlighting that context specific applications such as the warning color appeal, is an important antecedent to users' behavioral intentions. Third, we uniquely applied the actual behavior in combination with the perceived risk and color appeal dimensions, which adds more precision to the overall results. In the information security context, measuring actual behavior is far more realistic and should strengthen results in the specific warning context. Fourth, our study clarified the relationships between culture and color appeal/perceived risk/behavioral intention constructs in such a way that we found no moderating effect is present in those relationships for our full model. However, we found different color applications (red, yellow and green) to produce different effects in a different culture. More precisely, although yellow seems to be positively associated to BEH and PR in U.S. culture, this is not the case for Indian culture. This finding is quite new in the warning context. Past studies [31] also found that blue and grey are more appealing than yellow in an eCommerce context. Our study reveals that, in the unique warning message context, cultural environment does play a vital role in the color selection process. That is, the color application has a different effect across different cultures and, as such, does not seem to have the same level of efficiency on the user's behavior from one culture to another. Finally, we found red to be the most appealing color in the U.S. culture context. However, we did not find yellow to be the most appealing in Indian culture. This can be explained by the fact that as users in India are repeatedly socialized to US color standards on websites, then their behavior could be expected to be pulled away from India norms. Also, this indicates that another color application should be tested to understand if, for example, white is the most efficient color for the warning message context in Indian culture.

\subsection{Practical insights}

Our research has several practical insights. First, warning message designers should take into account the color application and which color best communicates to users. More precisely, color seems to be an important design element that can be more or less efficient across different cultures. That is, the introduction of other colors (e.g., yellow for invalid certificates in the Chrome web browser) should be done with precaution as it may lead to lower appeal among users which could, ultimately, impact users' behavioral intentions. Second, we found that cues to action strongly impact the perceived risk, which, in turn, impacts the behavioral intentions. This is an interesting finding as it suggests that users are willing to pay more attention to warning messages if they are more informed about the hazards that are communicated through the warning message. This is especially useful in the organizational context as employees could be better informed, educated and trained on the risks related to being non-compliant. Hence, effective communication could be an important factor in leveraging organizational security.

\subsection{Limitations and future research}

Our study has several limitations. Our sample was general Internet users, which could limit some of our conclusions in such a way that, for example, employees from organizations could behave differently in their organizational setup than general Internet users. Second, we focused only on two different countries. It would be better to add additional cultures, such as African or Asian cultures, which could demonstrate different behaviors in the warning context. Future research could extend our findings by including 
additional color schemes to test if certain colors have higher or lower psychological arousal with users. In other words, to further understand how users' experiences would be impacted if different color applications are presented to them.

\section{Conclusion}

Our research investigated cross-cultural effectiveness of the warning message to understand key drivers of users' behavioral intentions toward being more compliant. Supported by the color-incontext theory, we found that culture is an important dimension in the specific warning message context in which color appeal is a salient antecedent to behavioral intentions in culturally distinct countries. We derive several theoretical contributions and practitioners' insights.

\section{References}

[1] Elliot, A.J., and Maier, M.A., "Color-in-Context Theory", Advances in experimental social psychology, 45(2012, pp. 61-125.

[2] Elliot, A.J., and Maier, M.A., "Color Psychology: Effects of Perceiving Color on Psychological Functioning in Humans", Annual review of psychology, 65(2014, pp. 95120 .

[3] O'connor, Z., "Colour Harmony Revisited", Color Research \& Application, 35(4), 2010, pp. 267-273.

[4] Wogalter, M.S., "Purposes and Scope of Warnings", Handbook of Warnings. Lawrence Erlbaum Associates, Mahwah, NJ, 2006, pp. 3-9.

[5] Coleman, S., "The Minnesota Income Tax Compliance Experiment: Replication of the Social Norms Experiment", Available at SSRN 1393292, 2007,

[6] Goldstein, N.J., Cialdini, R.B., and Griskevicius, V., "A Room with a Viewpoint: Using Social Norms to Motivate Environmental Conservation in Hotels", Journal of consumer Research, 35(3), 2008, pp. 472-482.

[7] Schultz, P., and Tabanico, J.J., "Criminal Beware: A Social Norms Perspective on Posting Public Warning Signs*", Criminology, 47(4), 2009, pp. 1201-1222.

[8] Modic, D., and Anderson, R., "Reading This May Harm Your Computer: The Psychology of Malware Warnings", Computers in Human Behavior, 41(2014, pp. 71-79.
[9] Silic, M., Silic, D., and Oblakovic, G., "The Effects of Colour on Users' Compliance with Warning Banner Messages across Cultures", ECIS 2016, 2016

[10] Shi, J., Zhang, C., and Jiang, F., "Does Red Undermine Individuals' Intellectual Performance? A Test in China", International Journal of Psychology, 50(1), 2015, pp. 81-84.

[11] Noiwan, J., and Norcio, A.F., "Cultural Differences on Attention and Perceived Usability: Investigating Color Combinations of Animated Graphics", International Journal of Human-Computer Studies, 64(2), 2006, pp. 103-122.

[12] Russo, P., and Boor, S., "How Fluent Is Your Interface?: Designing for International Users", in (Editor, 'ed.'^'eds.'): Book How Fluent Is Your Interface?: Designing for International Users, ACM, 1993, pp. 342-347.

[13] Cacioppo, J.T., Gardner, W.L., and Berntson, G.G., "Beyond Bipolar Conceptualizations and Measures: The Case of Attitudes and Evaluative Space", Personality and Social Psychology Review, 1(1), 1997, pp. 3-25.

[14] Elliot, A.J., and Covington, M.V., "Approach and Avoidance Motivation", Educational Psychology Review, 13(2), 2001, pp. 73-92.

[15] Lang, P.J., "The Emotion Probe: Studies of Motivation and Attention", American psychologist, 50(5), 1995, pp. 372.

[16] Chen, M., and Bargh, J.A., "Consequences of Automatic Evaluation: Immediate Behavioral Predispositions to Approach or Avoid the Stimulus", Personality and social psychology Bulletin, 25(2), 1999, pp. 215-224.

[17] Derryberry, D., and Reed, M.A., "Anxiety and Attentional Focusing: Trait, State and Hemispheric Influences", Personality and individual differences, 25(4), 1998, pp. 745-761.

[18] Förster, J., Friedman, R.S., Özelsel, A., and Denzler, M., "Enactment of Approach and Avoidance Behavior Influences the Scope of Perceptual and Conceptual Attention", Journal of Experimental Social Psychology, 42(2), 2006, pp. 133146.

[19] Felt, A.P., Ainslie, A., Reeder, R.W., Consolvo, S., Thyagaraja, S., Bettes, A., Harris, H., and Grimes, J., "Improving Ssl Warnings: Comprehension and Adherence", in (Editor, 'ed.'^'eds.'): Book Improving Ssl Warnings: Comprehension and Adherence, ACM, 2015, pp. 2893-2902.

[20] Gnambs, T., Appel, M., and Oeberst, A., "Red Color and Risk-Taking Behavior in Online Environments", PLoS ONE, 10(7), 2015, pp. e0134033.

[21] Maier, M.A., Elliot, A.J., and Lichtenfeld, S., "Mediation of the Negative Effect of Red on Intellectual 
Performance", Personality and Social Psychology Bulletin, 2008,

[22] Ten Velden, F.S., Baas, M., Shalvi, S., Preenen, P.T., and De Dreu, C.K., "In Competitive Interaction Displays of Red Increase Actors' Competitive Approach and Perceivers' Withdrawal", Journal of Experimental Social Psychology, 48(5), 2012, pp. 1205-1208.

[23] Feltman, R., and Elliot, A.J., "The Influence of Red on Perceptions of Relative Dominance and Threat in a Competitive Context", Journal of Sport \& Exercise Psychology, 33(2), 2011, pp. 308-314.

[24] Kliger, D., and Gilad, D., "Red Light, Green Light: Color Priming in Financial Decisions", The Journal of SocioEconomics, 41(5), 2012, pp. 738-745.

[25] Guéguen, N., "Does Red Lipstick Really Attract Men? An Evaluation in a Bar", International Journal of Psychological Studies, 4(2), 2012, pp. p206.

[26] Guéguen, N., and Jacob, C., "Clothing Color and Tipping Gentlemen Patrons Give More Tips to Waitresses with Red Clothes", Journal of Hospitality \& Tourism Research, 38(2), 2014, pp. 275-280.

[27] Sokolik, K., Magee, R.G., and Ivory, J.D., "Red-Hot and Ice-Cold Web Ads: The Influence of Web Ads' Warm and Cool Colors on Click-through Rates", Journal of Interactive Advertising, 14(1), 2014, pp. 31-37.

[28] Wogalter, M.S., Conzola, V.C., and Smith-Jackson, T.L., "Research-Based Guidelines for Warning Design and Evaluation", Applied ergonomics, 33(3), 2002, pp. 219-230.

[29] Goldberg, J.H., Stimson, M.J., Lewenstein, M., Scott, N., and Wichansky, A.M., "Eye Tracking in Web Search Tasks: Design Implications", in (Editor, 'ed.'^'eds.'): Book Eye Tracking in Web Search Tasks: Design Implications, ACM, 2002, pp. 51-58.

[30] Lichtlé, M.-C., "The Effect of an Advertisement's Colour on Emotions Evoked by Attitude Towards the Ad: The Moderating Role of the Optimal Stimulation Level", International Journal of Advertising, 26(1), 2007, pp. 37-62.

[31] Cyr, D., Head, M., and Larios, H., "Colour Appeal in Website Design within and across Cultures: A Multi-Method Evaluation", International Journal of Human-Computer Studies, 68(1), 2010, pp. 1-21.

[32] Cunningham, S.M., "The Major Dimensions of Perceived Risk", Risk taking and information handling in consumer behavior, 1967, pp. 82-108.

[33] Mcknight, D.H., Choudhury, V., and Kacmar, C., "Developing and Validating Trust Measures for E-
Commerce: An Integrative Typology", Information systems research, 13(3), 2002, pp. 334-359.

[34] Singh, N., Zhao, H., and Hu, X., "Cultural Adaptation on the Web: A Study of American Companies' Domestic and Chinese Websites", Journal of Global Information Management (JGIM), 11(3), 2003, pp. 63-80.

[35] Lin, C.S., Wu, S., and Tsai, R.J., "Integrating Perceived Playfulness into Expectation-Confirmation Model for Web Portal Context", Information \& Management, 42(5), 2005, pp. 683-693.

[36] Antony, S., Lin, Z., and Xu, B., "Determinants of Escrow Service Adoption in Consumer-to-Consumer Online Auction Market: An Experimental Study", Decision Support Systems, 42(3), 2006, pp. 1889-1900.

[37] Bettman, J.R., "Perceived Risk and Its Components: A Model and Empirical Test", Journal of Marketing Research (JMR), 10(2), 1973,

[38] Featherman, M.S., and Pavlou, P.A., "Predicting EServices Adoption: A Perceived Risk Facets Perspective", International journal of human-computer studies, 59(4), 2003, pp. 451-474.

[39] Gewald, H., and Dibbern, J., "Risks and Benefits of Business Process Outsourcing: A Study of Transaction Services in the German Banking Industry", Information \& Management, 46(4), 2009, pp. 249-257.

[40] Bandura, A., "Self-Efficacy: Toward a Unifying Theory of Behavioral Change", Psychological review, 84(2), 1977, pp. 191.

[41] Ajzen, I., and Fishbein, M., Understanding Attitudes and Predicting Social Behavior, Prentice-Hall, Englewood Cliffs, NJ, 1980.

[42] Schepers, J., and Wetzels, M., "A Meta-Analysis of the Technology Acceptance Model: Investigating Subjective Norm and Moderation Effects", Information \& Management, 44(1), 2007, pp. 90-103.

[43] Wu, J., and Lederer, A., "A Meta-Analysis of the Role of Environment-Based Voluntariness in Information Technology Acceptance", MIS Quarterly, 33(2), 2009, pp. 419-432.

[44] Crossler, R.E., Johnston, A.C., Lowry, P.B., Hu, Q., Warkentin, M., and Baskerville, R., "Future Directions for Behavioral Information Security Research", Computers \& Security, 32(2013, pp. 90-101.

[45] Anderson, C.L., and Agarwal, R., "Practicing Safe Computing: A Multimedia Empirical Examination of Home Computer User Security Behavioral Intentions", MIS quarterly, 34(3), 2010, pp. 613-643. 
[46] Mahmood, M.A., Siponen, M., Straub, D., Rao, H.R., and Raghu, T., "Moving toward Black Hat Research in Information Systems Security: An Editorial Introduction to the Special Issue", MIS quarterly, 34(3), 2010, pp. 431-433.

[47] Berlin, B., and Kay, P., Basic Color Terms: Their Universality and Evolution, Univ of California Press, 1991.

[48] Kay, P., Berlin, B., and Merrifield, W., "Biocultural Implications of Systems of Color Naming", Journal of Linguistic Anthropology, 1(1), 1991, pp. 12-25.

[49] Barber, W., and Badre, A., "Culturability: The Merging of Culture and Usability", in (Editor, 'ed.'^'eds.'): Book Culturability: The Merging of Culture and Usability, 1998, pp. 1-10.

[50] Cyr, D., and Trevor-Smith, H., "Localization of Web Design: An Empirical Comparison of German, Japanese, and United States Web Site Characteristics", Journal of the American society for information science and technology, 55(13), 2004, pp. 1199-1208.

[51] Bagozzi, R.P., and Yi, Y., "On the Use of Structural Equation Models in Experimental Designs", Journal of marketing Research, 1989, pp. 271-284.

[52] Hofstede, G., Culture's Consequences: International Differences in Work-Related Values, sage, 1984.

[53] Ng, B.-Y., Kankanhalli, A., and Xu, Y.C., "Studying Users' Computer Security Behavior: A Health Belief Perspective", Decision Support Systems, 46(4), 2009, pp. 815-825.

[54] Johnston, A.C., and Warkentin, M., "Fear Appeals and Information Security Behaviors: An Empirical Study", MIS quarterly, 34(3), 2010, pp. 549-566.

[55] Bulgurcu, B., Cavusoglu, H., and Benbasat, I., "Information Security Policy Compliance: An Empirical Study of Rationality-Based Beliefs and Information Security Awareness", MIS quarterly, 34(3), 2010, pp. 523-548.

[56] Paternoster, R., and Simpson, S., "Sanction Threats and Appeals to Morality: Testing a Rational Choice Model of Corporate Crime", Law and Society Review, 1996, pp. 549583.

[57] Kock, N., Warppls 4.0 User Manual, ScriptWarp Systems, Laredo Texas USA, 2010.

[58] Fornell, C., and Larcker, D.F., "Evaluating Structural Equation Models with Unobservable Variables and Measurement Error", Journal of Marketing Research (JMR), 18(1), 1981,

[59] Podsakoff, P.M., Mackenzie, S.B., Lee, J.-Y., and Podsakoff, N.P., "Common Method Biases in Behavioral
Research: A Critical Review of the Literature and Recommended Remedies", Journal of applied psychology, 88(5), 2003, pp. 879.

[60] Liang, H., Saraf, N., Hu, Q., and Xue, Y., "Assimilation of Enterprise Systems: The Effect of Institutional Pressures and the Mediating Role of Top Management", MIS quarterly, 31(1), 2007, pp. 59-87.

[61] Chin, W.W., "The Partial Least Squares Approach to Structural Equation Modeling", Modern methods for business research, 295(2), 1998, pp. 295-336.

[62] Falk, R.F., and Miller, N.B., A Primer for Soft Modeling, University of Akron Press, 1992.

[63] Bravo-Lillo, C., Cranor, L.F., Downs, J.S., and Komanduri, S., "Bridging the Gap in Computer Security Warnings: A Mental Model Approach", IEEE Security \& Privacy, 9(2), 2011, pp. 18-26.

[64] Anderson, B., Vance, T., Kirwan, B., Eargle, D., and Howard, S., "Users Aren't (Necessarily) Lazy: Using Neurois to Explain Habituation to Security Warnings", 2014,

[65] Silic, M., "Understanding Colour Impact on Warning Messages: Evidence from Us and India", in (Editor, 'ed.'^'eds.'): Book Understanding Colour Impact on Warning Messages: Evidence from Us and India, ACM, 2016, pp. 2954-2960.

[66] Silic, M., Silic, D., and Oblakovic, G., "Restrictive Deterrence: Impact of Warning Banner Messages on Repeated Low-Trust Software Use", 18th International Conference on Enterprise Information Systems (ICEIS 2016), 2016, pp. 435-442.

[67] Silic, M., Barlow, J., and Ormond, D., "Warning! A Comprehensive Model of the Effects of Digital Information Security Warning Messages", The 2015 Dewald Roode Workshop on Information Systems Security Research, IFIP, 2015, pp. 1-32.

[68] Silic, M., and Cyr, D., "Colour Arousal Effect on Users' Decision-Making Processes in the Warning Message Context", in (Editor, 'ed.'^'eds.'): Book Colour Arousal Effect on Users' Decision-Making Processes in the Warning Message Context, Springer, 2016, pp. 99-109. 